\title{
Sistem Online Message Gateway Untuk Presensi Sidik Jari
}

\author{
Wisnu Jati Rogo Juni ${ }^{1}$, Banu W. Yohanes ${ }^{2}$, Saptadi Nugroho ${ }^{3}$ \\ Program Studi Sistem Komputer, \\ Fakultas Teknik Elektronika dan Komputer, \\ Universitas Kristen Satya Wacana, Salatiga \\ ${ }^{1}$ wisnu.jrj@gmail.com, 2banu.yohanes@staff.uksw.edu, ${ }^{3}$ saptadi_nugroho@yahoo.com
}

\begin{abstract}
Ringkasan
Sistem presensi di dalam makalah ini adalah sistem absensi menggunakan sidik jari yang diintegrasikan dengan online message gateway sebagai pengontrol tambahan. Data presensi yang diperoleh dari perangkat keras pemindai sidik jari secara waktu nyata dikirimkan ke komputer server untuk disimpan ke dalam database lalu dikirim dengan menggunakan bot (robot program otomatis) ke perangkat komputer/smartphone yang dituju. Pengujian yang telah dilakukan adalah pengujian koneksi alat dan laptop, pengujian database, pengujian kejadian waktu nyata pada saat proses pemindaian sidik jari dan pengiriman data ke komputer server serta pengujian pengiriman pesan dengan menggunakan bot. Dari hasil pengujian tersebut diperoleh prosentase keberhasilan sebesar $100 \%$.
\end{abstract}

Kata kunci: absensi sidik jari, bot, Online Message Gateway

\section{Pendahuluan}

Sistem presensi dengan menggunakan sidik jari sudah banyak dilakukan di instansi pemerintah, sekolah, perkantoran, pertokoan, dan instansi - instansi lainya misalnya aplikasi presensi perkuliahan berbasis fingerprint telah dibuat untuk diterapkan di sistem informasi Institut Teknologi Sepuluh November Surabaya [1], aplikasi sistem presensi yang diterapkan di Sekolah Menengah Atas Negeri 9 Manado digunakan untuk memperbaiki sistem absensi secara manual [2]. Sistem absensi siswa berbasis bot telegram juga diterapkan di SMK PGRI 1 Tangerang [3]. Selain dengan menggunakan fingerprint, Radio Frequency Identification (RFId) juga digunakan untuk sistem kehadiran perkuliahan [4]. Namun beberapa sistem presensi yang telah dibuat belum dilengkapi dengan fitur Online Message Gateway. Fitur tersebut sangat berguna dalam proses pengawasan data presensi. Sistem presensi yang dilengkapi dengan fitur online message gateway bisa digunakan di sekolah. Para orang tua siswa bisa memantau lewat aplikasi pesan secara online apakah anaknya benar-benar masuk untuk mengikuti pelajaran di sekolah atau tidak. Penggunaan konsep pemrograman berbasis object diterapkan di dalam sistem aplikasi ini [5]. Diagram hubungan antar entitas digunakan untuk merancang database sistem presensi ini [6]. Dalam makalah ini dirancang sistem Online Message Gateway untuk presensi sidik jari untuk tujuan pengawasan secara waktu nyata. 


\section{Perancangan Sistem}

Sistem Online Message Gateway untuk presensi sidik jari terdiri dari alat pemindai sidik jari, jaringan Local Area Network (LAN), komputer server dan perangkat keras Android. Gambar 1 menunjukan Skema perangkat keras sistem presensi sidik jari. Gambar 2 merupakan diagram alir sistem secara keseluruhan. Pada saat user melakukan absensi, data hasil pemindaian sidik jari dikirimkan ke komputer server untuk dapat diolah sesuai dengan format perintah yang didefinisikan di antarmuka pemrogramman aplikasi untuk dikirimkan ke pengguna online message application yang dituju dan lalu disimpan ke dalam database. Alat pemindai sidik jari digunakan perangkat keras Solution X100-C sedangkan online message application digunakan aplikasi Telegram [7].

Hubungan antar entitas di dalam database yang dibangun ditunjukkan di Gambar 3. Di dalam hubungan antar entitas terdapat tabel Person dan tabel Presensi. Setiap ID Person yang berhasil melakukan pemindaian sidik jari dicatat di dalam tabel Presensi.

Aplikasi program dari sistem ini dirancang untuk bisa menerima data identitas orang yang berhasil melakukan pemindaian sidik jari dari lebih dari satu alat pemindai sidik jari yang terhubung dengan jaringan komputer secara waktu nyata. Data yang telah diterima tersebut disimpan ke dalam database dan dilakukan proses lebih lanjut untuk mengirimkan data tersebut ke Online Message Application pada perangkat tujuan. Online Message Application yang digunakan dalam percobaan ini adalah aplikasi pesan online Telegram. Antarmuka user di dalam perangkat lunak dapat dilihat pada Gambar 5.

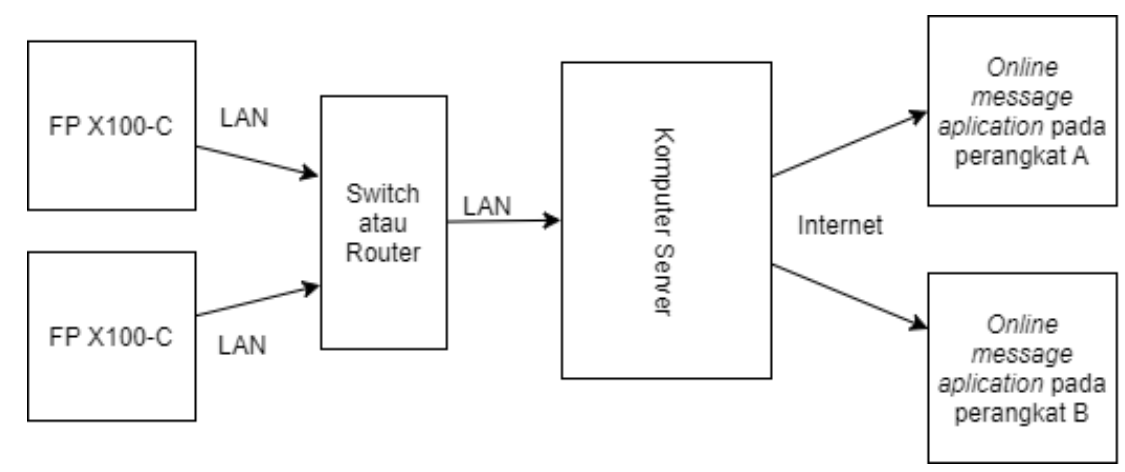

Gambar 1. Skema Perangkat Keras Sistem Online Message Gateway untuk Presensi Sidik Jari

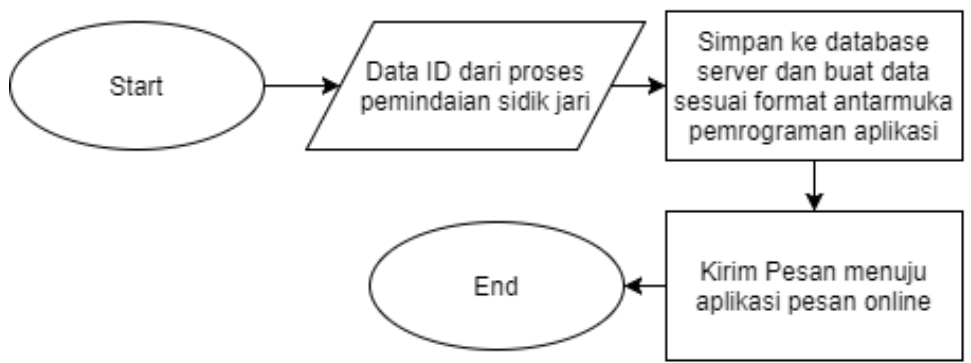

Gambar 2. Diagram Alir Sistem Online Message Gateway untuk Presensi Sidik Jari 
Sistem Online Message Gateway Untuk Presensi Sidik Jari Wisnu Jati Rogo Juni, Banu W. Yohanes, Saptadi Nugroho

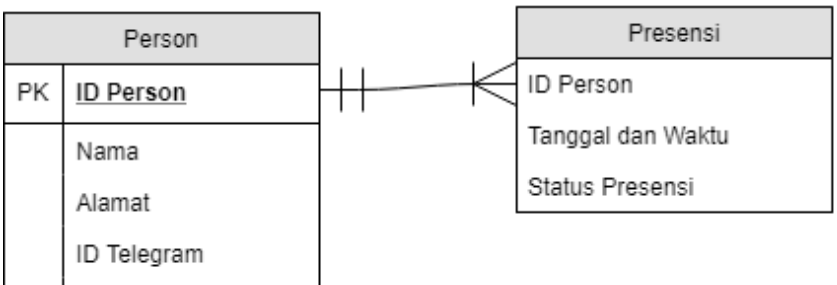

Gambar 3. Entity Relationship Diagram Sistem Online Message Gateway untuk Presensi Sidik Jari

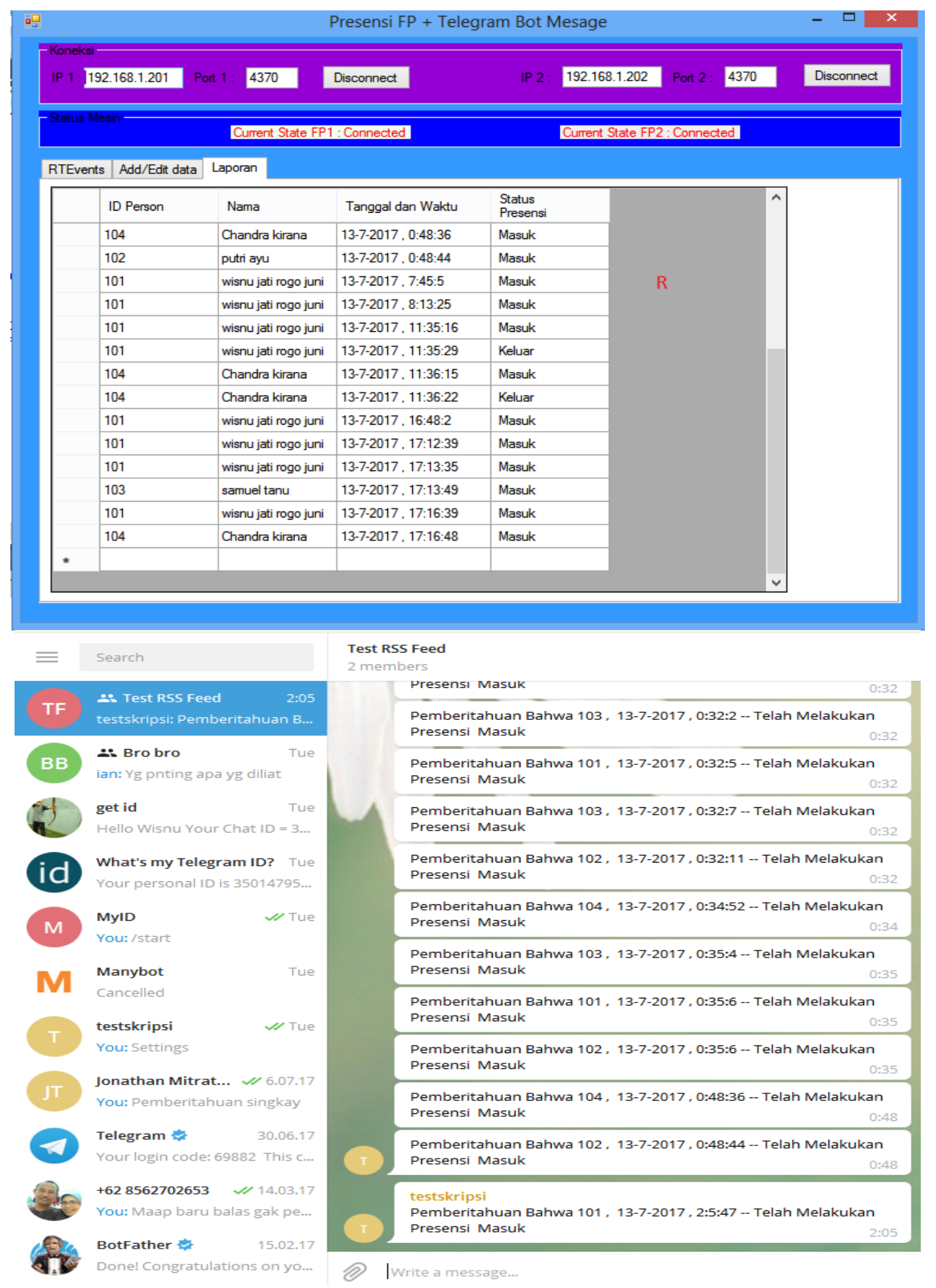

Gambar 4. Tampilan antarmuka dan telegram PC saat menerima pesan pemberitahuan absensi 


\section{Pengujian dan Analisis}

Pengujian sistem Online Message Gateway untuk presensi sidik jari dilakukan dengan beberapa kasus yaitu sebagai berikut.

1. Pengujian koneksi alat absensi dengan komputer

2. Pengujian proses manipulasi data pada database

3. Pengujian pengiriman data identitas hasil pemindaian Sidik Jari ke komputer server

4. Pengujian pengiriman pesan menggunakan bot ke aplikasi pesan online di pengguna

Dari hasil pengujian sistem Online Message Gateway untuk presensi sidik jari diperoleh tingkat keberhasilan $100 \%$. Pengujian lain juga dilakukan dengan cara menjalankan aplikasi program sistem ini selama 24 jam. Identitas orang yang melakukan pemindaian sidik jari dapat terekam ke dalam database dengan baik.

Dari Gambar 4 dapat dilihat bahwa pesan pemberitahuan absensi berhasil dikirimkan dan diterima saat alat absensi menerima absensi masuk atau keluar (dalam kondisi alat absensi terkoneksi dengan PC, program yang dibuat dan internet).

\section{Kesimpulan}

Sistem Online Message Gateway untuk presensi sidik jari dapat digunakan di beberapa instansi seperti sekolah agar orang tua murid dan pihak sekolah dapat memantau kehadiran anak di sekolah. Dari beberapa proses pengujian seperti pengujian koneksi alat absensi dengan komputer, pengujian penambahan, perubahan, penghapusan dan penampilan data dari database ke antarmuka pengguna, pengujian kejadian waktu nyata pada saat dilakukan pemindaian sidik jari dengan perangkat pemindai dan pengiriman data identitas orang yang berhasil melakukan pemindaian ke komputer server, pengujian pengiriman pesan menggunakan bot menuju aplikasi pesan online di pengguna memiliki tingkat keberhasilan $100 \%$. Data akan ditunda pengirimannya dari perangkat pemindai sidik jari ke komputer server apabila terjadi kondisi kabel jaringan komputer yang tidak tersambung. Data tersebut akan segera dikirimkan ke komputer server dari alat pemindai apabila koneksi jaringan tersambung kembali.

\section{Daftar Pustaka}

[1] Noval Aditya Muhammad, Febriliyan Samopa, Radityo Prasetianto Wibowo, Pembuatan Aplikasi Presensi Perkuliahan Berbasis Fingerprint (Studi Kasus : Jurusan Sistem Informasi Institut Teknologi Sepuluh Nopember Surabaya), JURNAL TEKNIK POMITS Vol. 2, No. 1, (2013) ISSN: 2337-3539.

[2] Alfien S.Rintjap, Sherwin R.U.A, Sompie, Oktavian Lantang, Aplikasi Absensi Siswa Menggunakan Sidik Jari di Sekolah Menengah Atas Negeri 9 Manado, e-journal Teknik Elektro dan Komputer (2014), ISSN: 2301-8402.

[3] Anonym, 2017, Sistem Absensi Siswa Berbasis Bot Telegram dan SMS. https://www.pgri.sch.id/2017/08/01/sistem-absensi-siswa-berbasis-bot-telegram-dansms/, diakses pada 1 September 2017.

[4] Eko Budi Setiawan, Bobi Kurniawan, Perancangan Sistem Absensi Kehadiran Perkuliahan dengan Menggunakan Radio Frequency Identification (RFId), Jurnal CoreIT, Vol.1, No.2, Desember 2015, ISSN: 2460-738X. 
[5] James Gosling, Bill Joy, Guy Steele, Gilad Bracha, Alex Buckley, The Java ${ }^{\circledR}$ Language Specification Java SE 8 Edition, 2015.

[6] Carlos Coronel, Steven Morris, Peter Rob, Database Systems: Design, Implementation \& Management, Ninth Edition, 2010.

[7] Anonym. 2013. Telegram Home, [online]. Available: https://telegram.org/, diakses pada 6 April 2017. 
